\title{
History of Xindu Guihu Garden through Vernacular Landscape Symbol Analysis
}

\author{
Dingying Ye ${ }^{1}$, Yuanyuan Jiang ${ }^{1}$, Chunyang Liu ${ }^{1}$ \\ ${ }^{1}$ College of Landscape Architecture of Sichuan Agricultural University, China
}

Keywords: semiotics; vernacular landscape symbol; Xindu Guihu; historical context analysis

\begin{abstract}
There are variety of landscape symbols in Xindu-Guihu Garden, which carry different cultural meaning and serve as the reflections of the history and evolution of the garden. Based on semiotic theories, different cultural symbols of different historical stages are firstly summarized and classified in this paper for general understanding. Based on field survey and symbol collection, certain landscape symbols of different historical stages are analyzed in detail to serve as an evidence of the garden's historical evolution. Vernacular landscape symbol analysis is then promoted as an approach to study the history and evolution of landscape architectures.
\end{abstract}

\section{Introduction}

Chinese culture symbols, through generations of historical evolution, are also being extensively applied in landscape architectures. Different symbol reflects different social economy and aesthetic ideology status of the particular historical stage. Vernacular landscape symbol analysis therefore provides a new research direction for the study of history of landscape architectures.

Landscape architecture in Chengdu, known as Xishu Gardens, has unique landscape character that is quite different from North Royal Gardens and those Jiangnan Private Gardens. Xishu Gardens, due to its local strength, is rich in various vernacular landscape resources of profound cultural connotation. With historical development and evolution, landscape architecture in Chengdu has formulated an unique vernacular landscape symbolic system. The history and connotation study and analysis of these symbols is of great importance for the best application of these symbols in future landscape architectures.

\section{Concept of Vernacular Landscape Symbol and its Classification}

Vernacular landscape symbol refers to the landscape symbols that are spontaneously or semi-spontaneously formulated upon people's living habit, their recognition of the land and nature and the fitness of these pattern to a certain spacial pattern. These symbols are identifiable in the feature of signans, designatum and reference [1]. Designatum refers to the visual form of the landscape, e.g. space, material, structure and constitutional elements etc. Signans means the connotation and meaning these vernacular and geological symbols imply. Reference refers to the specific symbols, such as decoration pattern, totem, landscape furniture etc.

According to the research results of the characteristics of vernacular landscape in academic circles [2] and in combination with the semiotic theory [3], two features of vernacular landscape symbol can be drawn here: a) natural and local; b) cultural and historical. Based on these two features, vernacular landscape symbols can be divided into two categories:

Local image \& symbol: it refers to the images or symbols that are shaped by influencing factors such as natural condition, historical background, change of the time and local climate, customs and traditions. The images or symbols formulated upon such factors, whether in its original form or symbolically expressed, are all locally featured and are full of local charm.

Historical image \& symbol: it refers to the images or symbols recording or reflecting certain historical events or describing spirit and morality of certain historical figures. The ancient builders, in a way of expressing their honor to the great historical figures they admire, used to introduce the 
relevant elements of their admired figures or events to the construction of the garden. That is why there are so many historical image and symbols applied in traditional landscape architectures.

\section{Historical Evolution of Vernacular Landscape Symbol in Xindu Guihu Garden}

\subsection{Field Survey and Symbol Collection}

A through field survey and vernacular landscape symbol collection of Xindu Guihu Garden was carried out by the research group based on survey routes planning, survey questionnaire design, grid division, GPS approach etc. The specific symbol categories appeared in Xindu Guihu garden are concluded based on careful calculation and analysis. (see Table 1 below):

Table 1 Classified vernacular landscape symbols appeared in Xindu Guihu Garden

\begin{tabular}{|c|c|c|c|}
\hline Category & Dynasty & Implication & $\begin{array}{c}\text { Frequency } \\
\text { (representative symbol) }\end{array}$ \\
\hline Botanical Pattern & Tang & $\begin{array}{l}\text { Different category carries } \\
\text { different meaning }\end{array}$ & 23 \\
\hline $\begin{array}{l}\text { Narrative Pattern (Brick } \\
\text { sculptures) }\end{array}$ & Han & Life records of that period & 7 \\
\hline $\begin{array}{l}\text { Calligraphy \& Painting } \\
\text { Pattern } \\
\text { (Birds \& Flower Pattern) }\end{array}$ & Qing & $\begin{array}{l}\text { Different category carries } \\
\text { different meaning }\end{array}$ & 2 \\
\hline Cloud Pattern & Tang and Song & Graceful and elegant & 1 \\
\hline Yunlei Pattern & Shang and Zhou & Power and order & 1 \\
\hline Cloud and Dragon Pattern & Ming and Qing & Power & 1 \\
\hline Beast Pattern & $\begin{array}{l}\text { Appear in each } \\
\text { Dynasty }\end{array}$ & $\begin{array}{l}\text { Different category carries } \\
\text { different meaning }\end{array}$ & 2 \\
\hline Twisted Pattern & Tang & Auspiciousness and fortune & 5 \\
\hline $\begin{array}{l}\text { Volume Grass Grain } \\
\text { Pattern }\end{array}$ & Song & Good luck and happiness & 3 \\
\hline Auspicious Pattern & Qing & Good wishes & 1 \\
\hline Fang-Sheng Pattern & Tang & Festive and auspiciousness & 2 \\
\hline Gold Ingot-Shaped Pattern & Ming and Qing & Endless fortune & 1 \\
\hline Animal Pattern & $\begin{array}{l}\text { Appear in each } \\
\text { Dynasty }\end{array}$ & $\begin{array}{l}\text { Different category carries } \\
\text { different meaning }\end{array}$ & 4 \\
\hline Dragon Pattern & Tang and Song & Power and fortune & 1 \\
\hline Geometrical Pattern & $\begin{array}{l}\text { Appear in each } \\
\text { Dynasty }\end{array}$ & Power and order & 13 \\
\hline
\end{tabular}

There are total of 15 symbol categories found in Xindu Guihu Garden, among which the botanic pattern, geometrical pattern and narrative pattern are frequently appeared, respectively occupying $34.3 \%, 19.4 \%$ and $10 \%$ (mainly brick sculpture type) of the total symbols.

\subsection{Historical Evidence}

Located in southwest of Xindu county, Guihu Garden is a comprehensive architecture functioning as a courier station garden, memorial garden, literature garden and public garden. Constructed in Shuhan period and prospered in earlier Tang Dynasty, Guihu Garden (originally as Nan Ting) has formulated its unique landscape feature through more than 1300 years' history.

Shuhan Dynasty--Brick Sculpture Highlights the Characteristic Landscape symbol. Xindu in history was under the jurisdiction of Shu State. In the period of Han dynasties, Weichang, an officer in Shuhan Zhangwu period, used to build lakes and dams to irrigate farm land. In memory of his contributions, people began to call the lake Weihu. At that time, the lake was located in an administrative unit defined as"Ting”, which was the the former body of Guihu lake. 
Brick sculptures are the brick artworks appeared in ancient graves. This form of art work was discovered in archaeological findings such as silk paintings, mural frescos and lacquer paintings. (see Fig. 1). Among them, Sichuan brick sculptures in Han Dynasty constitutes an important part of local history of Sichuan. Patterns on the bricks are variety in type, uniformed in style and harmoniously in outlook, all casting the social and cultural life of Shuhan period, e.g. the prevalence of luxurious funeral, worship of divine figure and social life of every aspect. The brick works at that time are "grand and profound" in artistic feature and represent the top art of Han dynasties, and also the precious treasure in artistic history.

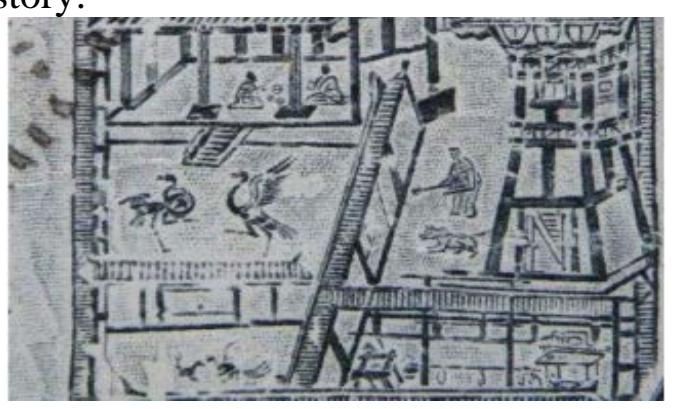

Fig. 1 Han Brick sculpture

In Xindu Guihu Garden, brick sculptures are found in structures like landscape pavement, fences of the wall and bridge pavement. Some of the bricks are in local style, with the theme of "Hunting" and " Ryhsyy Images " etc (see Fig. 2 and Fig. 3). Patterns representing other Sichuan regions are also recognizable. These brick sculptures are located in a way that they can be easily identified and read by visitors. Guihu lake has remained the " large water surface" structure since Shuhan period and has not been changed through alternations of dynasties. The shape of the lake, due to the limits of city wall and streets, it is not applicable to conduct mountain and lake construction. It remains therefore, a narrow and long square surface outlook. Walking through the mountain and lake, and amid these narrative brick sculptures telling the story of ancient Shuhan, an overwhelming Taoist and historical charm fills the whole environment.

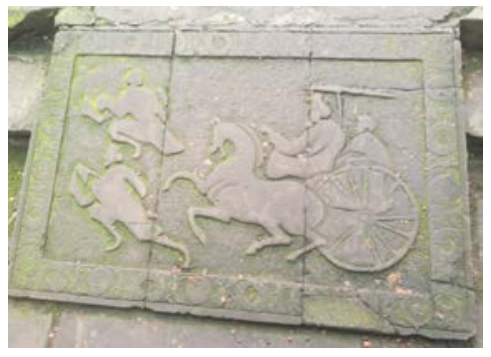

Fig. 2 Hunting pattern on stone bridge

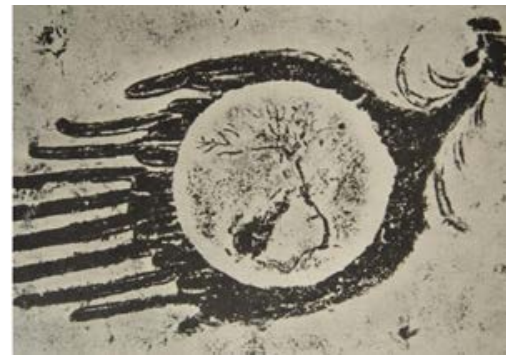

Fig. 3 Ryhsyy images on pavement architectures

Guihu garden provides a great example of brick sculpture application among Xishu Gardens. On one hand, it helps to formulate the specialty of the garden and on the other hand, it is also a garden in which visitors to experience the historical charm. The frequent application of brick sculptures on bridges, pavement and fences is very helpful in leaving visitors with great impression of them.

Sui, Tang and Song Dynasties-- Twisted Plants Pattern and Fang-Sheng Pattern Cast Vivid Detail of Landscape symbol. Compared with other Xishu Gardens, there are plenty of twisted plant patterns 
and geometric Fang-Sheng patterns found in Guihu Garden, which, according to "The Evolution Research of Chinese Traditional Patterns", are identical to the same patterns in Tang and Song Dynasty. These patterns are delicate and meticulous in style and are mainly with the theme of botanical subjects like plum, orchid, bamboo and chrysanthemum. The twisted patterns are more of plain and elegant style (see Fig.4). The meticulous pattern style is closely related to the prospering historical reform in Tang and Song Dynasty and well matches the landscape structure of "Nan Ting". The landscape symbols applied during this period were aimed to create a garden landscape of "trees and plants, birds and flowers”, making it a beautiful and comfortable public garden for mass citizens.
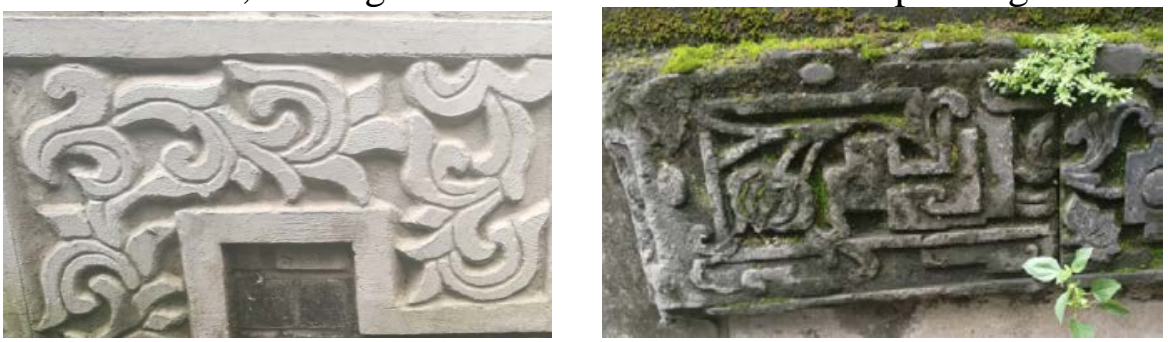

Fig. 4 Twisted plant pattern (honeysuckle, chrysanthemum)

In the eighteenth year of Emperor Sui Wendi, Xindu County was moved to the current location. The construction of walls and city structures began to commence, where the lake was enclosed to the inner side of south city wall. The administrative unit of "Ting" was then abolished. Some literature scholars were appointed as local officers, who for both purpose of their landscape pursuit and political achievement, developed "Nan Ting" using the power of their authority. "Nan Ting", at that time located next to the Xindu courier station, was developed into a government managed public garden for literature scholar and celebrity gatherings and public recreation. Catering to the public artistic taste, the gorgeous botanic pattern and auspicious Fang-Sheng pattern were adopted (see Fig. 5). In Song Dynasty, the name of "Nan Ting" was replaced by "Xindu Yi", as the meaning of letter "Ting" was replaced by letter "Yi" of courier station connotation. There were recreation architectures like "Pingyuan Xuan" for visitors to enjoy the view of the garden, and some inscriptions and notable boards from famous officials and scholars were already existed in the garden. The symbols began to match the style of lake and mountain [4], tress and fountains favored in Song Dynasty. Plants patterns in this period also began to change to the fresh and meticulous style from the former mellow and tactful style (see Fig. 6). Twisted plant pattern also changed from gorgeous Tang style to the meticulous style (see Fig. 7)

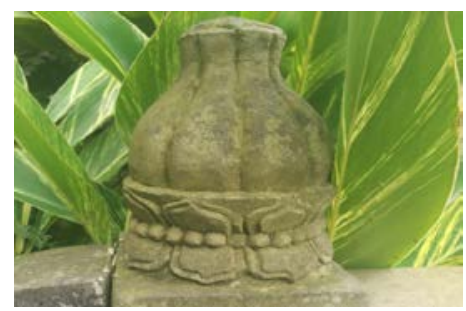

Fig. 5 Symbolic Lotus pattern in Tang Dynasty

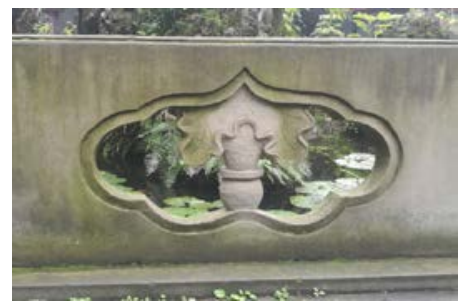

Fig. 6 Symbolic lotus and vase pattern in Song Dynasty 


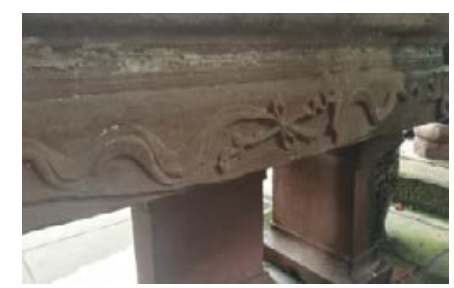

Fig. 7 Twisted plant pattern changed from

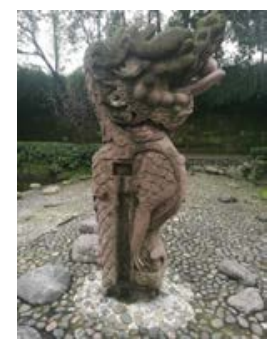

Fig. 8 The dragon sculpture complicated expression to the simple and tender style

Ming and Qing Dynasty--Dragon Pattern Applied as Main Landscape symbol. The dragon pattern applied in Xindu Guihu Garden is most distinct in the form of sculpture (see Fig. 8). According to "Chinese Symbols", dragon pattern, in Ming and Qing Dynasty, was gradually becoming a symbol of "power, auspiciousness and fortune". The dragon pattern in Guihu Garden is an evidence of garden construction history in Ming and Qing Dynasty--the history from Yang Shengan (style name of Yang Shen) in Ming Dynasty to the construction managed by county magistrate in the period of Emperor Daoguang.

Visitors are attracted by the dragon sculpture in the garden and stay to take photos, which is a good way to demonstrate the garden's landscape culture. The dragon sculpture, as located in the water front, resembles an old man fishing on the river, which thematically echos the famous line in Lin Jiang Xian, a famous Song poetry written by Yang Shen, the memorial figure of the lake: "White-haired fishermen work on the shoals".

The ingenuity of the landscape symbols in Xindu Guihu Garden, according to modern maintenance construction, is that on one hand, they become part of the landscape marking system of the garden, and on the other hand, the symbols not only become the harmonious parts of the responding stylistic landscapes (e.g. Lotus Pond) but also provides a historical reference for the trace and application of such ancient symbol systems.

\section{Conclusion}

In this paper, we have analyzed vernacular landscape symbols appeared in Xindu Guihu Garden and found that vernacular landscape symbol, characterized by the perfect combination of history and landscape, is expecting a potential development in future landscape construction. During the process of China's urbanization, less attention has been payed on the respect and protection of great historical and cultural relics, resulting in history and culture fracture and the extinction of traditional cultural symbols. Traditional cultural symbols, however, is an unique way delivering the overall charm of certain age in aspects of urban culture, history, politics and economy. Chinese traditional cultural symbols are formulated through long years development and different symbol serves as a condensed manifestation of social and cultural status in a certain historical stage. It is, therefore, important to protect these historical and cultural elements and rebuild these traditional symbols. Xishu Garden construction in other Sichuan regions shall also follow this mode.

Reviewing comprehensively of China history, the symbol system, from the images and symbols of primitive society to the classified shape arts in late feudal society, has delivered certain constant themes which are commonly found in each historical stage. These common themes take various forms and uses different patterns in different dynastic stages, the change of which are often adapt to the material, technique, craftsmanship and social trend of the certain age. The symbols, therefore, are 
usually distinct in characteristics of the specific stage and the specific region. In Xindu Guihu Garden, landscape symbols are various in forms, which are formulated under the influence of different political, economic, ideological and cultural background of different dynasties. These symbols are of great value the garden has preserved. In future landscape design, the landscape symbol application should follow the example of Xindu Guihu garden, so as to inherit the historical essence to the landscape construction and at the same time to further promote the development of vernacular landscape symbols.

\section{Acknowledgement}

Subsidy Program: "Historic Evolution of Vernacular Landscape Symbol in Chengdu and Its Application", A project 2016, No: JGYQ2016002, supported by "SiChuan Landscape and Recreation Research Center".

\section{References}

[1] Zhang Yuxin., Origin, Evolution and Landscape Characters of Xindu Guihu Garden, Sichuan Cultural Relics, 1999 (5) :58-61.

[2] Chen Zongming and Huang Huaxin, Introduction to Semiotics, Henan People's Publishing House (Zhengzhou, 2004).

[3] Zhang Yimian, Application of Chinese Traditional Decorative Patterns in Modern Design, [Building World, 2014.

[4] Li Li and Wu Shan, The Evolution Research of Chinese Traditional Patterns, Art Education Research, 2012 (1): 22-23. 